\title{
Positive Psychological Interventions and Chronic Non-Cancer Pain: A Systematic Review of the Literature
}

\author{
Joanne E. Iddon ${ }^{1}$ • Joanne M. Dickson ${ }^{2,3}$. \\ Jen Unwin ${ }^{4}$
}

Accepted: 21 November 2016 / Published online: 22 December 2016

(C) Springer International Publishing AG 2016

\begin{abstract}
Chronic pain is a multi-faceted, pervasive condition associated with significant psychosocial impairment. Positive psychological interventions (PPIs) are increasingly delivered in clinical settings, with recent research offering evidence supporting the application of PPIs in predominantly mental-health contexts. To date, no review has considered the impact of PPIs applied in physical-health settings. The aim of this systematic review is to collate the available evidence and identify psychosocial factors that can be improved via PPIs for individuals with chronic non-cancer pain. Particularly, the review focuses upon study outcomes considered to be conceptually-aligned with the aims of such interventions. A systematic search of five electronic databases was conducted utilising terms relating to chronic pain, positive psychological constructs and intervention outcomes. A total of 3289 articles were considered as part of
\end{abstract}

Joanne M. Dickson

j.dickson@ecu.edu.au; j.dickson@liv.ac.uk

Joanne E. Iddon

joanne.iddon@thewaltoncentre.nhs.uk

Jen Unwin

j.unwin@nhs.net

1 Complex Rehabilitation Unit, Mersey Care NHS Trust, Sid Watkins Building, Lower Lane, Liverpool L9 7LJ, UK

2 School of Arts and Humanities, Psychology Department, Edith Cowan University, (Building 30) 270 Joondalup Drive, Joondalup, WA 6027, Australia

3 Department of Psychological Sciences (Honorary Research Fellow), University of Liverpool, Whelan Building, Brownlow Hill, Liverpool L69 3GB, UK

4 Department of Clinical Health Psychology, Southport and Ormskirk Hospital NHS Trust, 5 Curzon Road, Southport PR8 6PL, UK 
the identification process. Eight studies were included in the final review upon deduplication and application of the review exclusion criteria. The effects of PPIs and methodological quality of studies varied greatly, though improvements in psychological well-being, hope, pain self-efficacy, happiness and life-satisfaction were evident. The results demonstrate PPIs can have beneficial effects for individuals living with chronic non-cancer pain. Methodological limitations, clinical implications and recommendations regarding future research are discussed.

Keywords Positive psychological intervention - Chronic pain · Psychosocial outcomes · Well-being · Systematic review

\section{Introduction}

The International Association for the Study of Pain (IASP 1994) defines chronic pain as pain which persists beyond the expected time for tissue healing to have taken place, typically reported to be pain which is present for three months or more since the initial onset. Chronic pain is an exceptionally broad category which encompasses a vast array of disorders and there is great variation with respect to distinct underlying mechanisms, causes and pain sites across pain conditions. Pain symptoms may also occur in the absence of medical cause or explanation (Jackson et al. 2009) and chronic pain is increasingly classified as "a disease in its own right" rather than just a symptom of a disorder (Niv \& Devor 2004, pp. 180).

Despite the diversity amongst the causes of onset, there is substantial overlap between the treatment and management options of chronic pain disorders and overarching psychological commonalities relating to the pain experience are evident across differing conditions (Turk et al. 2011). The personal impact of chronic pain is well-documented within the literature, with findings suggesting that individuals often experience significant impairments in relation to physical, social and psychological functioning (Smith et al. 2001) and reduced quality of life (Breivik et al. 2006).

Whilst not all individuals with chronic pain experience co-morbid mental health difficulties which meet diagnostic thresholds, it is widely accepted that those living with the chronic disease are at an elevated risk of experiencing increased psychological distress compared to non-clinical, healthy samples (McBeth et al. 2002). Pain-related distress is associated with a poor prognosis across various pain conditions (van der Windt et al. 2007; Boersma \& Linton 2006) and increased healthcare utilisation (Von Korff et al. 2007).

Current medical, pharmacological and surgical treatments which aim to ameliorate pain intensity and subsequent functional impairment demonstrate effects which are modest at best (Turk et al. 2011), prompting a growing realisation for the importance and consideration of psychosocial factors in relation to pain-related distress (Gatchel et al. 2007). The debilitating nature of chronic pain and its impact on both the individual and the global economy highlights the need for effective clinical interventions which aim to promote adaptive functioning and increase individuals' sense of well-being. 


\subsection{Psychological Models and Interventions}

Chronic pain is currently understood using biopsychosocial models which have been developed to extend beyond a purely biomedical understanding of chronic pain (Flor \& Turk 2011). These models recognise the significance of psychological and social factors in relation to the effects and maintenance of chronic pain, and have led to the development of a number of psychological interventions in this area over the past 50 years (Jensen \& Turk 2014). Traditional interventions have typically focused on identifying and reducing psychological deficits that pose risk factors for poor prognosis or pain-related outcomes.

More recently, psychological approaches and interventions based upon 'third wave' Cognitive-Behavioural approaches such as Acceptance and Commitment Therapy (ACT) (Dahl et al. 2004) and Mindfulness-Based Cognitive Therapy (MBCT) (Segal et al. 2002) are more frequently being applied in clinical practice with chronic pain populations. See Veehof et al. (2011) and Marikar Bawa et al. (2015) for reviews regarding the effectiveness of such interventions for individuals with chronic pain.

\subsubsection{Positive Psychological Interventions}

The idea of a paradigm shift away from a sole focus on pathology and reducing suffering and psychological distress is described in detail in Seligman and Csikszentmihalyi's (2000) seminal paper. The publication of this pivotal article has led to a rapid expansion in the positive psychology literature in a variety of clinical samples in both mental and physical health settings.

The positive psychology movement embraces an empirical approach which focuses upon the measurement of constructs such as happiness, quality of life and well-being (Lopez \& Snyder 2003). As the approach advanced and the literature base developed, a theoretical framework comprising three 'orientations to happiness' were proposed by Seligman (2002). Namely, the concepts of Pleasure, Engagement and Meaning. Seligman (2002) proposed that maximising positive emotions (Pleasure), seeking out activities which draw upon signature strengths to induce a sense of effortless involvement or flow (Engagement) and utilizing these strengths in the service of something greater than oneself (Meaning) contributed towards an individual's overall sense of well-being. Seligman later criticized his initial theory as being too simplistic, and added the concepts of pursuing meaningful relationships (Relationships) and experiencing a sense of accomplishment (Accomplishment) as important factors which support the cultivation of well-being (Seligman 2011). The relevance of developing psychological interventions in line with Seligman's (2011) five factors to enhance well-being and ameliorate depressive symptoms has been established in a recent randomized, placebocontrolled study (Gander et al. 2016).

Positive psychological interventions (PPIs) are increasingly applied in both online self-help and therapist-delivered formats with individuals and groups, with studies outlining effects of interventions which include expressing gratitude (Emmons \& McCullough 2003), positive writing (Wing et al. 2006) and practicing kindness (Otake et al. 2006). The effectiveness of such interventions has been evaluated in two meta-analyses to date (Sin \& Lyubomirsky 2009; Bolier et al. 2013) with results demonstrating enhancements in subjective and psychological well-being and a 
reduction in depressive symptoms. The vast majority of PPI studies to date have involved non-clinical samples and participants experiencing mood disorders such as anxiety or depression.

Review Objectives Whilst the effectiveness of traditional and more recent third CBT wave clinical interventions is well-documented within the chronic pain literature, little is known about the application and effects of PPIs in this clinical field. The aim of the present research is to conduct a systematic review of the relevant literature to collate the available evidence and identify psychosocial factors that can be improved via PPIs for individuals with chronic non-cancer pain.

\section{Method}

\subsection{Eligibility Criteria}

Establishing a single definition of what constitutes a PPI is somewhat problematic due to a lack of a common theoretical thread or framework upon which to base the content and structure of interventions. There is thus ongoing debate within the literature regarding the characterization of such interventions (Schueller et al. 2014; Bolier et al. 2014). It is recommended that rather than follow one specific definition, researchers are guided by criterion which encompass the overall aims of such approaches (Parks \& Biswas-Diener 2013). For instance, PPIs may incorporate therapeutic strategies based upon Seligman's (2011) theory to induce a global improvement in well-being, or be based upon alternative theories relating to the enhancement of specific psychological constructs still deemed to be relevant to positive psychology (such as hope or self-efficacy, for example). In a similar vein, it is important that dependent variables are appropriate and valid for the aims of the interventions. This presents a similar dilemma due to the evident variation in outcomes measured following PPIs within the literature. Furthermore, there is mounting evidence which suggests that although correlated, mental well-being and mental-illness are in fact independent continua (Keyes 2005). Rather than solely focus upon the move away from suffering and the maladaptive thought processes underpinning it, there is a need to appropriately quantify the shift people may make from initially being within an average range of psychological health to a position of flourishing (Hone et al. 2014). This is operationalised in the literature as striving towards an optimal or increased sense of emotional well-being, psychological well-being, and social well-being (Keyes 2011).

In line with existing chronic pain intervention literature and IASP (1994) classifications, a distinction between cancer and non-cancer pain was made due to several key medical and psychosocial differences between the diseases (Fordyce 2001). For example, the neurophysiological mechanisms and subsequent pharmacological treatments typically differ between malignant and non-malignant chronic pain (Schug \& Auret 2008). Similarly, psychological distress amongst cancer survivors who experience malignant pain may be exacerbated or maintained by the fear of the cancer prognosis worsening or reoccurring (Koch et al. 2013). Furthermore, a palliative care approach may be adopted for chronic pain associated with advanced cancer which would not be 
appropriate in the management of non-cancer pain. These key differences warrant that a distinction is made between the types of chronic pain within research.

For explorative purposes and reasons of inclusion within this relatively nascent division of the evidence base, we deemed it appropriate to utilize a mixed-methods model. This approach complements the research aim and allows for the integration of inferences derived from quantitative outcomes with the qualitative understanding of individuals' experiences. In line with existing reviews evaluating the impact of psychological interventions on the management of chronic pain (Williams et al. 2012), we chose to include only those studies which utilized adult samples. This is due to the notion that there may be variation regarding the presentation and treatment of pain between these two populations (McGrath 2005). The study inclusion criteria were therefore as follows:

- Adult participants aged over 18 years old.

- Participants with non-malignant pain for at least three months in duration since onset (and therefore classified as chronic).

- Studies investigating the effects of a PPI (including therapies explicitly developed according to positive psychology principles, exercises or specific techniques in selfhelp, individual and/or group formats) which aimed to develop, manipulate and/or induce positive variables (including emotions, behaviours or cognitions).

- Outcomes conceptually aligned with theoretical frameworks underpinning PPIs.

- Publication in a peer-reviewed journal; and

- Published in English

In accordance with the previous systematic review of general PPI outcomes (Bolier et al. 2013), studies which reported on the effectiveness of mindfulness and third-wave CBT interventions were excluded. Although it is arguable that such interventions aim to induce positive affect, in the context of the defined inclusion criteria these interventions are underpinned by therapeutic principles which fundamentally differ to those which form the core elements of positive psychological approaches. For example, mindfulness approaches encourage the development of a non-judgemental, purposeful awareness to the present moment which in turn reduces rumination of positive or future events (Jon Kabat-Zinn 2013). In contrast, interventions developed in accordance with positive psychology principles may encourage positive rumination and judgement of past events to induce positive affect (Larsen \& Prizmic 2004).

\subsection{Search Strategy}

A systematic literature search was carried out to capture the full scope of published literature. Chronic pain, well-being and positive psychological interventions are in themselves broad topics, though they were concretely defined by means of appropriate search terms to allow for a focused yet encompassing search of the available evidence. The terms utilized were developed based on a scoping exercise of the relevant literature and terminology used within the area, clinical experience and advice, and consultation with experts within the field.

The first step of the review consisted of searching the following databases for existing academic journal articles and reviews: DISCOVER, PubMed, Web of Science, 
Scopus and PsychInfo. The search terms were identified taking into account those used in existing reviews of the positive psychology evidence base (Bolier et al. 2013; Sin \& Lyubomirsky 2009) and the most commonly-used terminology within this area. The terms were then entered in four steps to accumulate relevant papers. Firstly, 'chronic pain OR long term pain' was entered, followed by 'AND positive psychol* OR optimism OR hope OR happ* OR gratitude'. Next, 'AND intervention OR treatment OR therap* OR management' was inputted. Finally, the terms 'AND wellbeing OR well-being OR "quality of life" OR QoL OR life satisfaction OR affect OR SWB' (referring to subjective well-being) were entered. Databases were searched for studies from inauguration to October 2015.

Key published experts in the positive psychology field were then contacted for published papers not previously identified and for studies due to be published over the next six months. The references of the two existing reviews of positive psychological interventions (Bolier et al. 2013; Sin \& Lyubomirsky 2009) were cross-checked, and the reference lists of the papers to be included in the review were also examined. Duplicate studies obtained throughout the search process were removed by means of auto and hand-searching methods as recommended (Qi et al. 2013).

Two reviewers independently selected eligible studies in two phases. The first phase involved selecting potentially-relevant papers by the title and abstract of the publication, and for the second phase selection was based upon the full-text article. There was complete agreement regarding the final articles selected for the review $(K=1)$.

\subsection{Quality Assessment}

The Quality Assessment Tool for Studies of Diverse Designs (QATSDD) (Sirriyeh et al. 2012) was used to assess the diverse range of studies. Originally developed for use with health service researchers by examining common quality indicators featured on existing checklists such as those developed by the Consolidated Standards of Reporting Trials (CONSORT), the Critical Appraisal Skills Programme (CASP) and the Strengthening the Reporting of Observational studies in Epidemiology (STROBE) guidelines, the QATSDD has shown good reliability and validity when assessing the risk of bias and quality of diverse study designs.

Although there are implications and subsequent limitations to consider when employing a more general tool for quality assessment, the QATSDD allowed for cross-comparisons between differing methodologies. Whilst this has its advantages, QATSDD total scores should be interpreted with some discretion as particular areas of significant methodological weaknesses may be concealed by perhaps less influential strengths in other areas, and vice versa. For example, a poor score on the item assessing the appropriateness of the study sample size may be obscured by a higher score merited from describing the study research setting in detail.

\subsection{Data Extraction}

First, the demographic data of the studies' participants were extracted, followed by information relating to the characteristics of the PPIs (such as the format and method of delivery of the intervention). The outcome measures used in the quantitative studies were then recorded, as was information relating to the 
methods of statistical analyses undertaken in the studies. Finally the study findings (including the significance values and effect sizes) were extracted. In line with the recommendations outlined by Schueller et al. (2014), outcome data and study findings were extracted if they were conceptually aligned with the aims and theoretical principles of positive psychology. For the two qualitative studies, details relating to the method of analyses (i.e., thematic) were extracted, followed by the overarching themes and subthemes reported in the studies. The data were recorded independently by two reviewers and there was complete agreement regarding the information included $(K=1)$.

\section{Results}

The electronic search yielded a total of 3282 records. A further six papers were identified through searching the reference lists of the final included articles one further paper was provided by a published author in the field. The two previous literature reviews of positive psychology interventions did not yield any relevant results.

Of the total 1655 records assessed during the initial screening phase, 27 were eligible for full-text assessment. The identification process and reasons for exclusion are reported in Fig. 1. A total of eight studies (reported in seven articles) met the inclusion criteria and were included in the final review. Of these, five utilized a quantitative pretest post-test design, one used an experimental single-case methodology and the remaining two papers reported qualitative outcomes.

\subsection{Characteristics of Included Studies}

Demographic information and details of the included studies and PPIs can be found in Table 1. The eight studies included a total of 307 participants, of which $211(68.7 \%)$ were female. The mean age of participants within individual studies (where reported) ranged from 49.5 to 78.3 years, though it is notable that Tse et al. (2010) specifically recruited older adults residing in nursing homes.

In most cases, the types of pain conditions experienced by participants varied significantly within individual studies. Two studies specified particular pain sites or type and one study examined chronic pain experiences as a result of a co-morbid disability. Of the quantitative studies, two included a control group as a comparator alongside the PPI group, and three studies reported data relating to longer-term followup time-points (ranging from 10-weeks to 12-months). Interestingly, all but one of the papers included in this review were published in 2014 or 2015 , indicating the somewhat nascent, but emerging nature of this area.

\subsection{Quality Assessment}

The individual item, total and percentage scores for quality assessment can be found in Table 2. There was considerable variability with regard to overall quality, with scores ranging from 23 to 36 out of a possible 42 (54.8\% and $85.7 \%$ respectively). Higher scores indicate a higher level of methodological and reporting quality. The sample sizes 


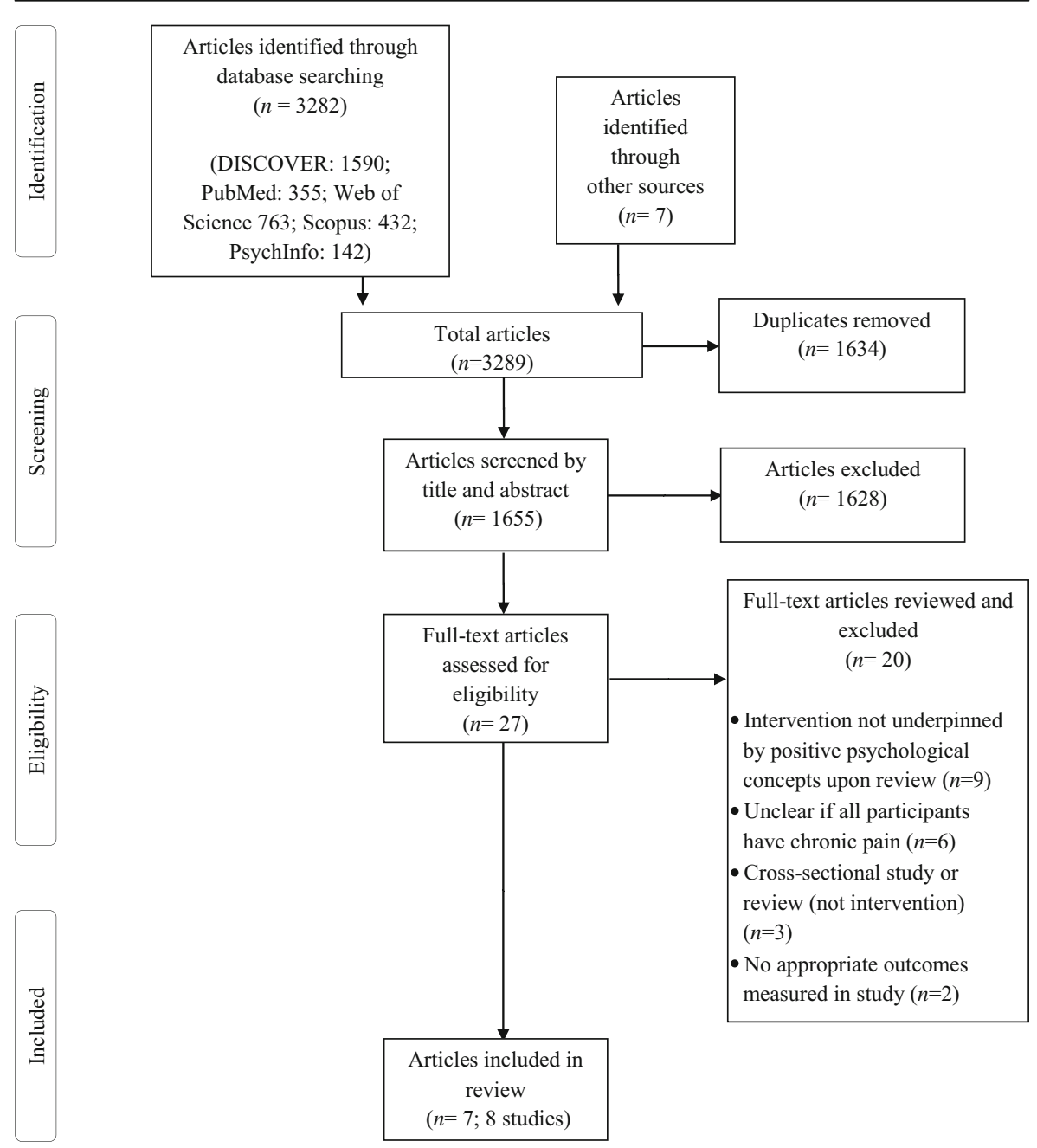

Fig. 1 Identification of included studies

of the quantitative studies were small in nearly all cases. Five studies employed pre-test post-test designs, and study limitations therefore mainly centred upon the lack of control or comparator groups and absence of longer-term data to assess for maintenance of effects.

\subsection{Overall PPI Outcomes}

The review findings are reported according to the methodology employed in the articles. The findings of the quantitative cohort studies are summarized according to the psychosocial outcomes targeted in the PPIs. For ease of interpretation the outcomes of the single-case study are reported independently, as is the summary of the qualitative findings. See Table 3 for information relating to the quantitative findings and qualitative themes. 


\begin{tabular}{|c|c|c|c|c|c|c|c|c|}
\hline 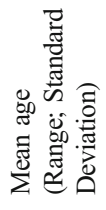 & 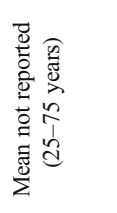 & 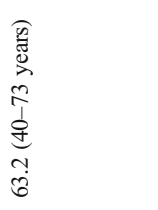 & 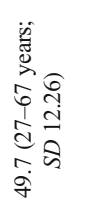 & 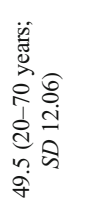 & 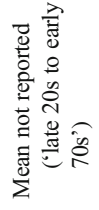 & 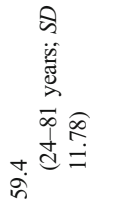 & 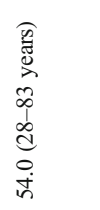 & 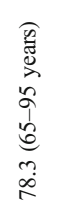 \\
\hline 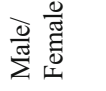 & $\stackrel{n}{\lambda}$ & $\stackrel{m}{\wedge}$ & $\stackrel{\infty}{\wedge}$ & $\overrightarrow{\widetilde{N}}$ & $\stackrel{\infty}{\vec{f}}$ & iे & $\begin{array}{l}\text { ô } \\
\text { ते }\end{array}$ & $\underset{\sim}{\infty}$ \\
\hline 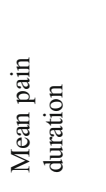 & 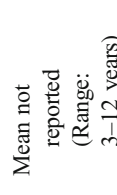 & 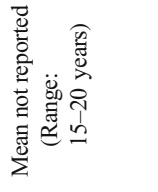 & 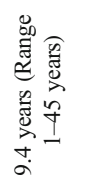 & 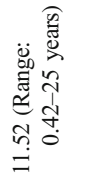 & 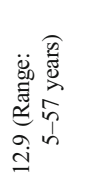 & 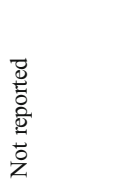 & 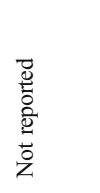 & 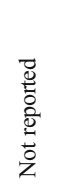 \\
\hline 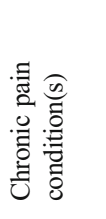 & 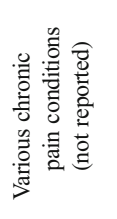 & 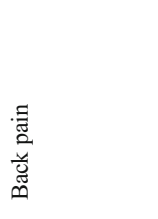 & 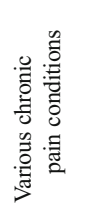 & 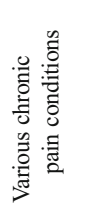 & 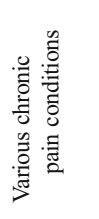 & 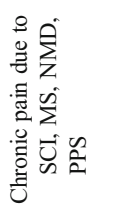 & 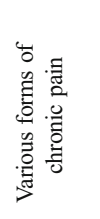 & 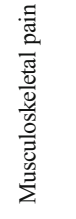 \\
\hline 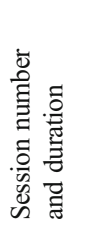 & 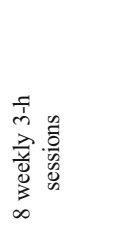 & 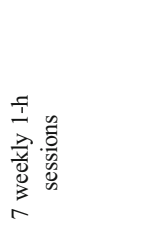 & 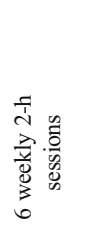 & 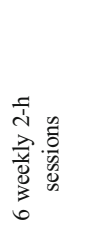 & 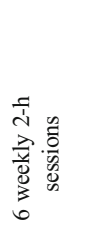 & 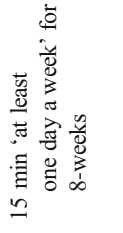 & 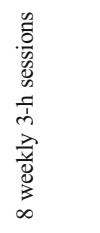 & 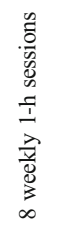 \\
\hline 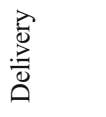 & 今े & 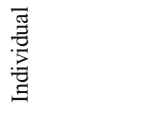 & 言 & 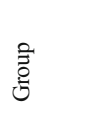 & $\begin{array}{l}\text { 离 } \\
\text { ثे }\end{array}$ & 莺 & $\begin{array}{l}\text { 亏ें } \\
\text { है }\end{array}$ & $\begin{array}{l}\text { 产 } \\
\text { ثे }\end{array}$ \\
\hline 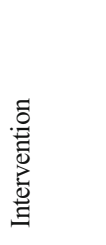 & 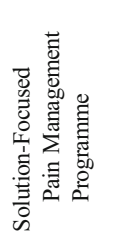 & 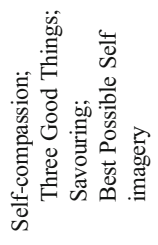 & 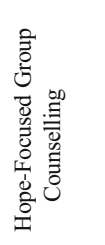 & 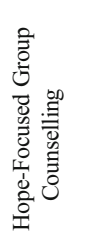 & 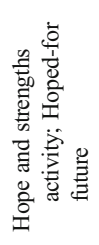 & 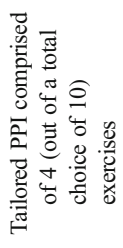 & 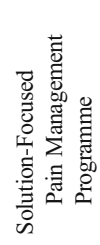 & 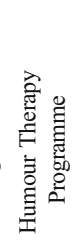 \\
\hline $\begin{array}{l}\text { E } \\
\text { 吾 }\end{array}$ & 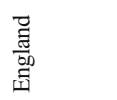 & 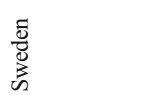 & 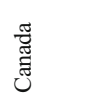 & $\begin{array}{l}\text { 烝 } \\
\text { Uू }\end{array}$ & 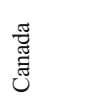 & 岕 & $\begin{array}{l}\overrightarrow{\vec{E}} \\
\text { 䓌 } \\
\text { 至 }\end{array}$ & 些离 \\
\hline$z$ & in & in & 인 & $\stackrel{J}{\sim}$ & $\simeq$ & 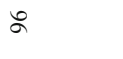 & $\infty$ & $尺$ \\
\hline 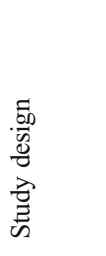 & 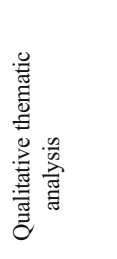 & 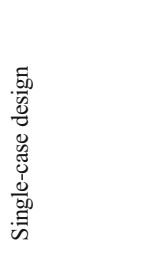 & 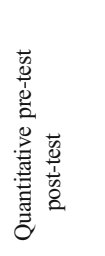 & 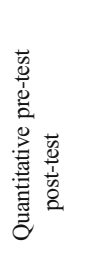 & 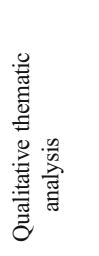 & 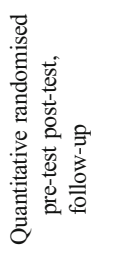 & 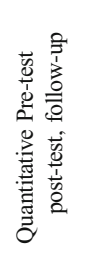 & 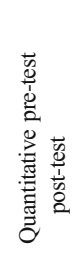 \\
\hline 泀 & 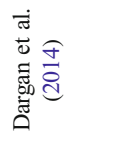 & 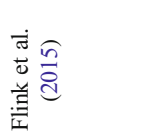 & 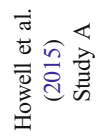 & 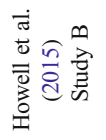 & 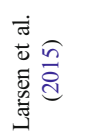 & 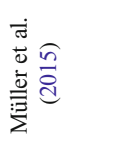 & 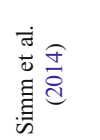 & 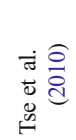 \\
\hline
\end{tabular}




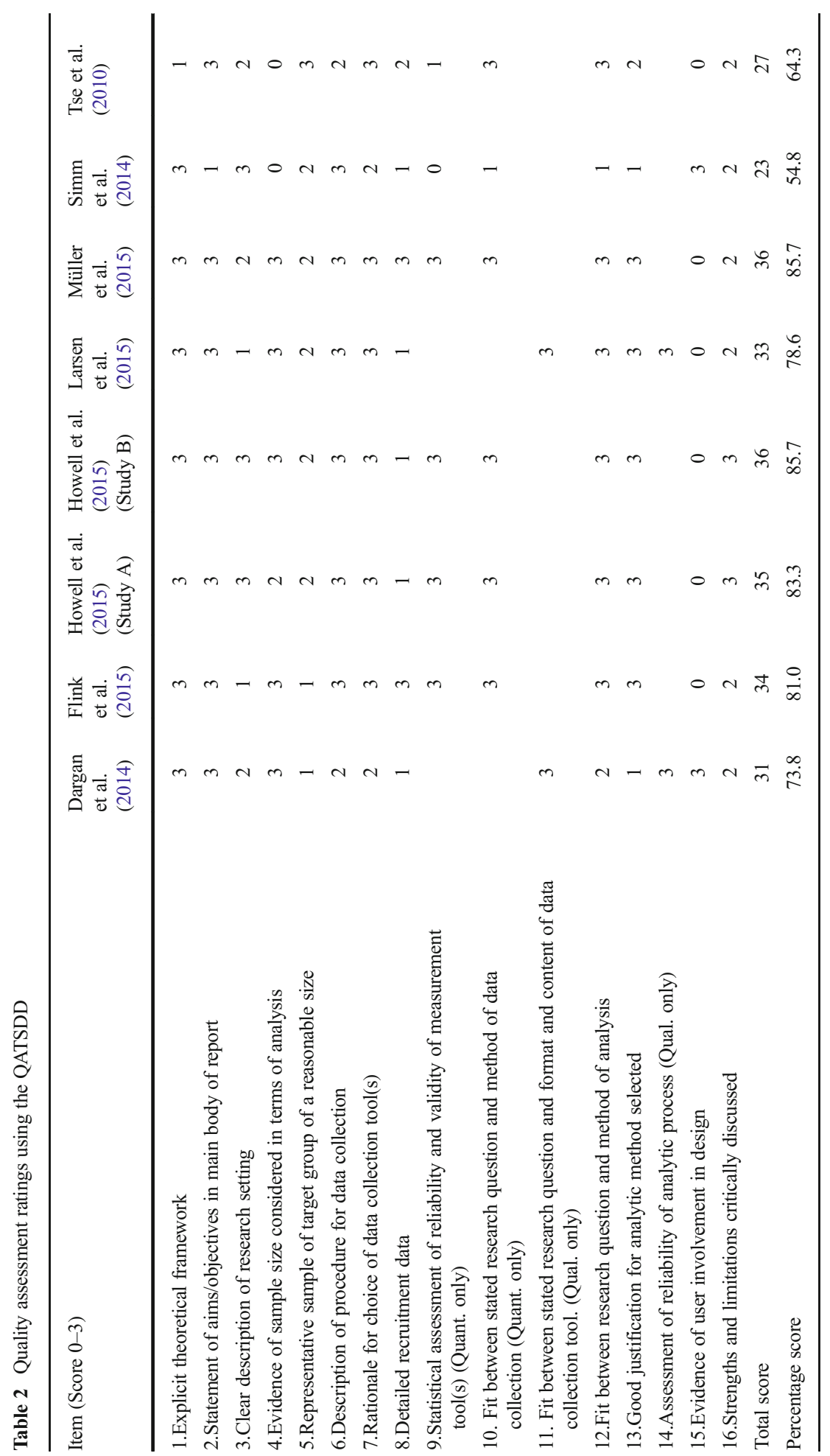




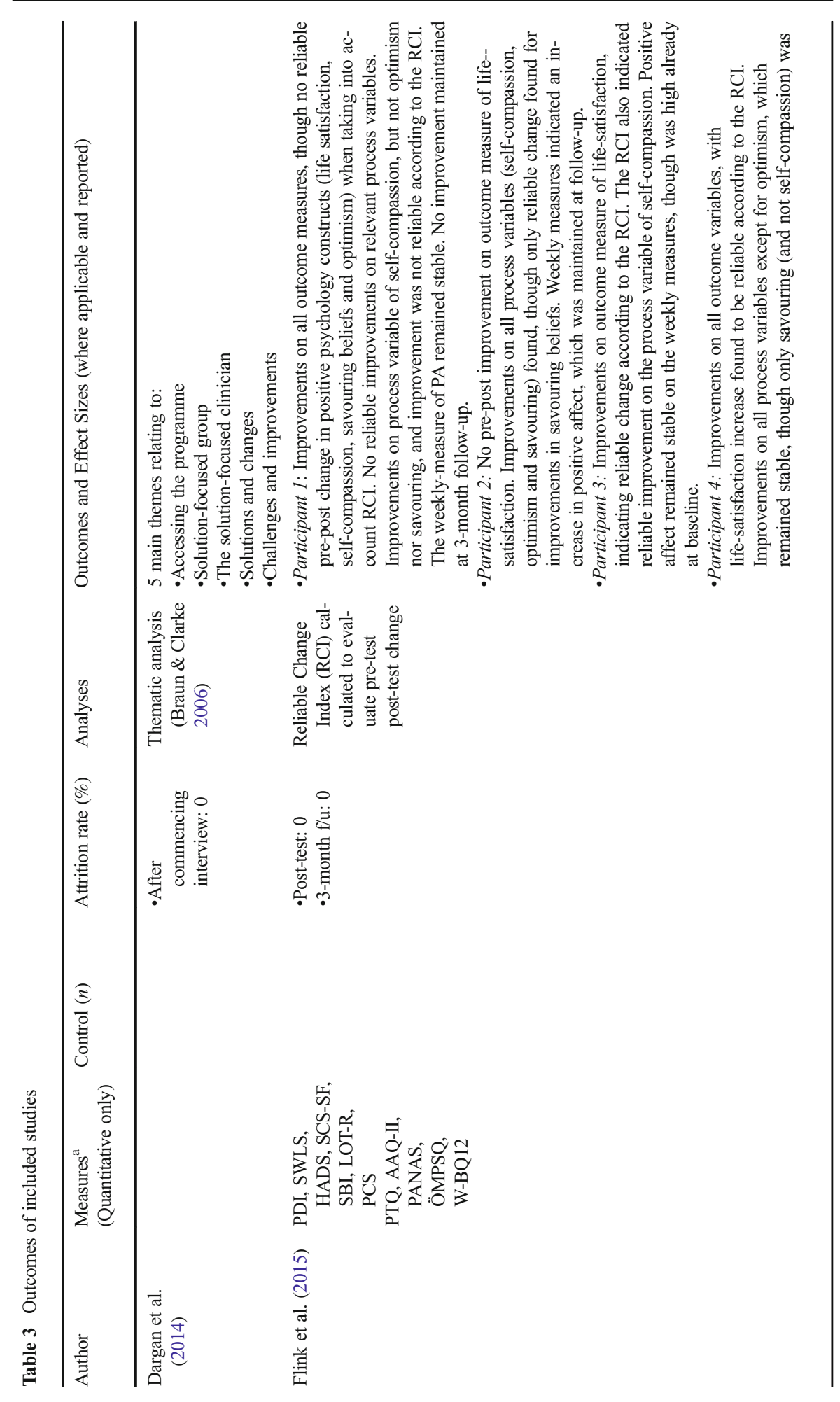




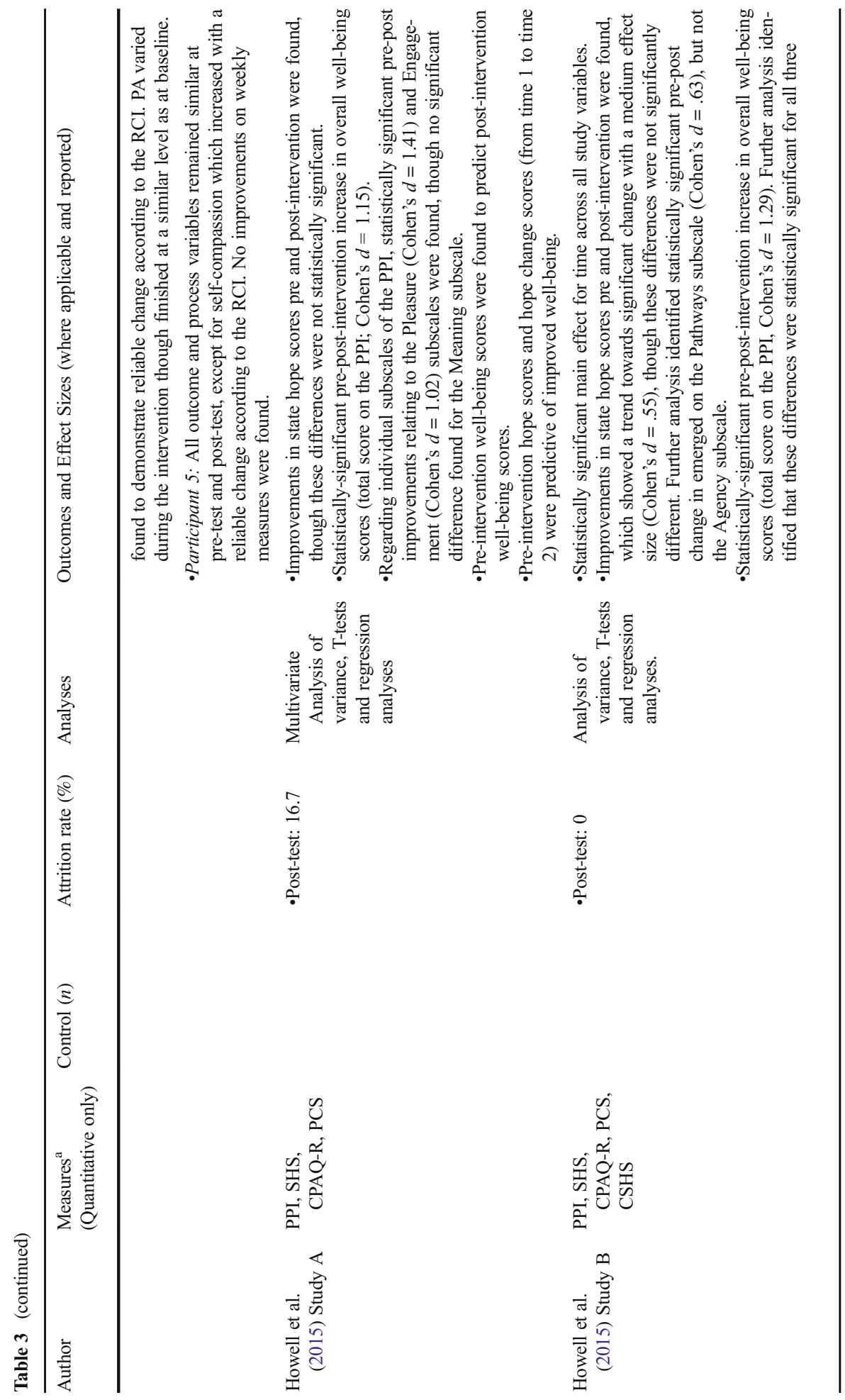




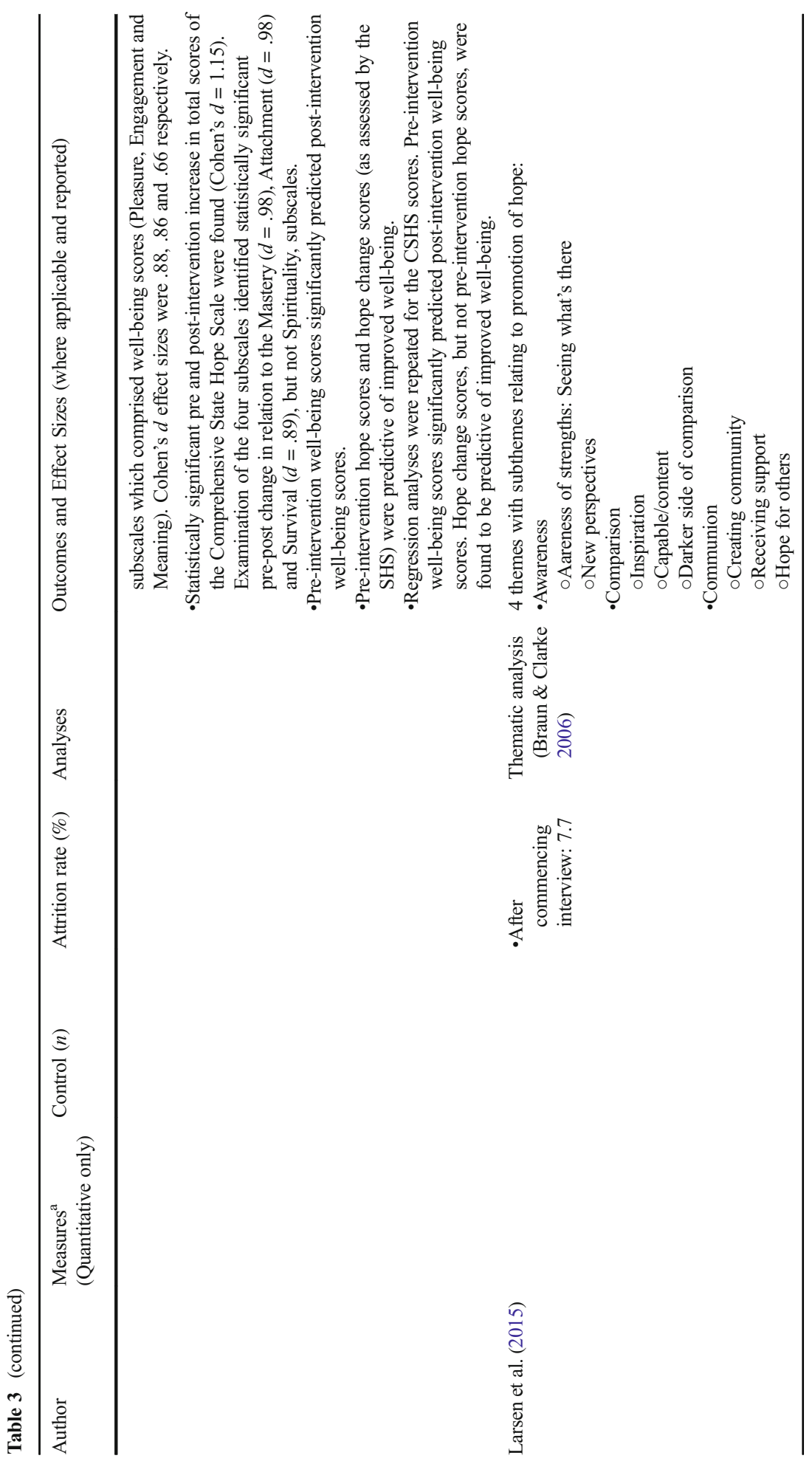




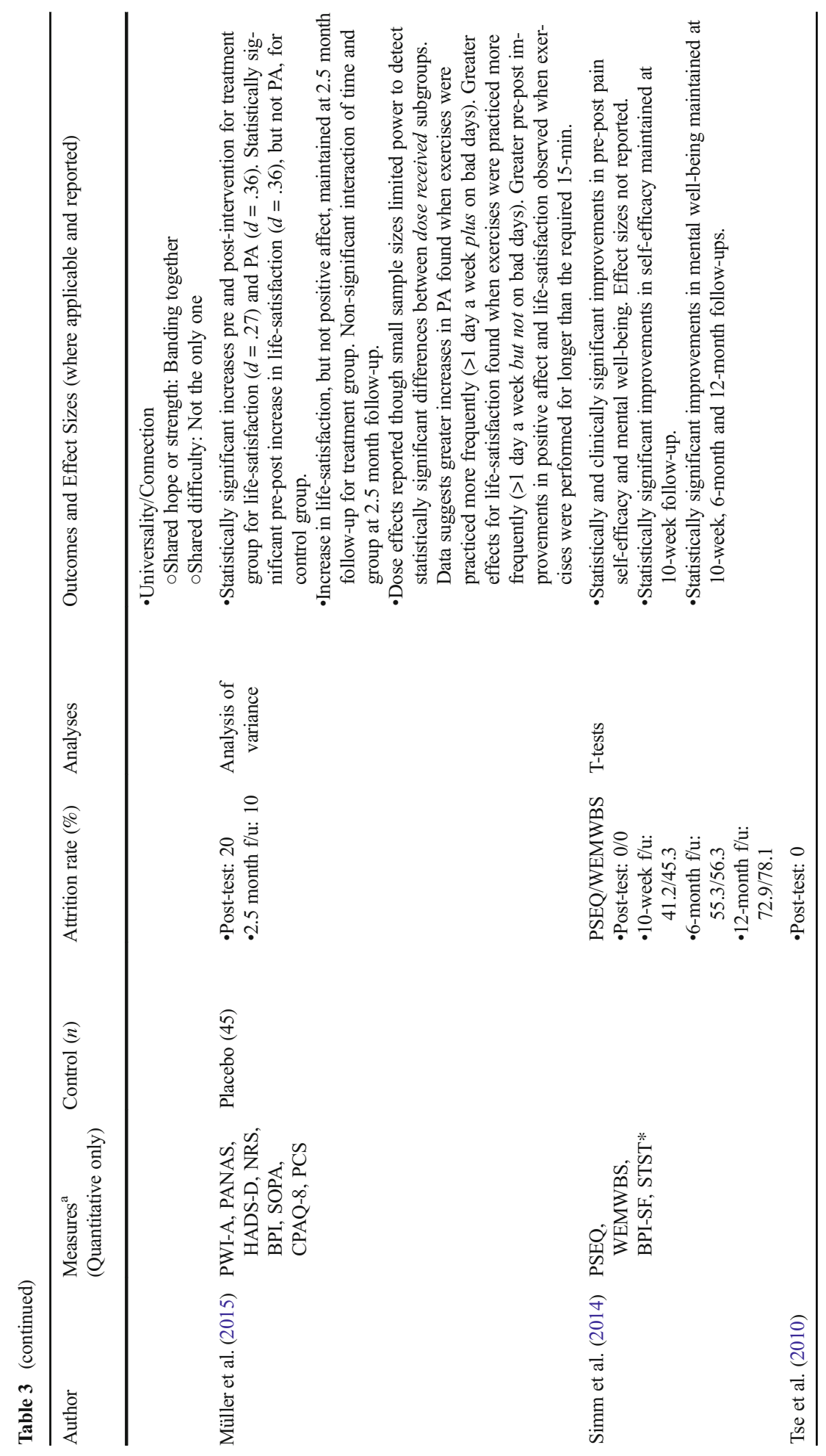




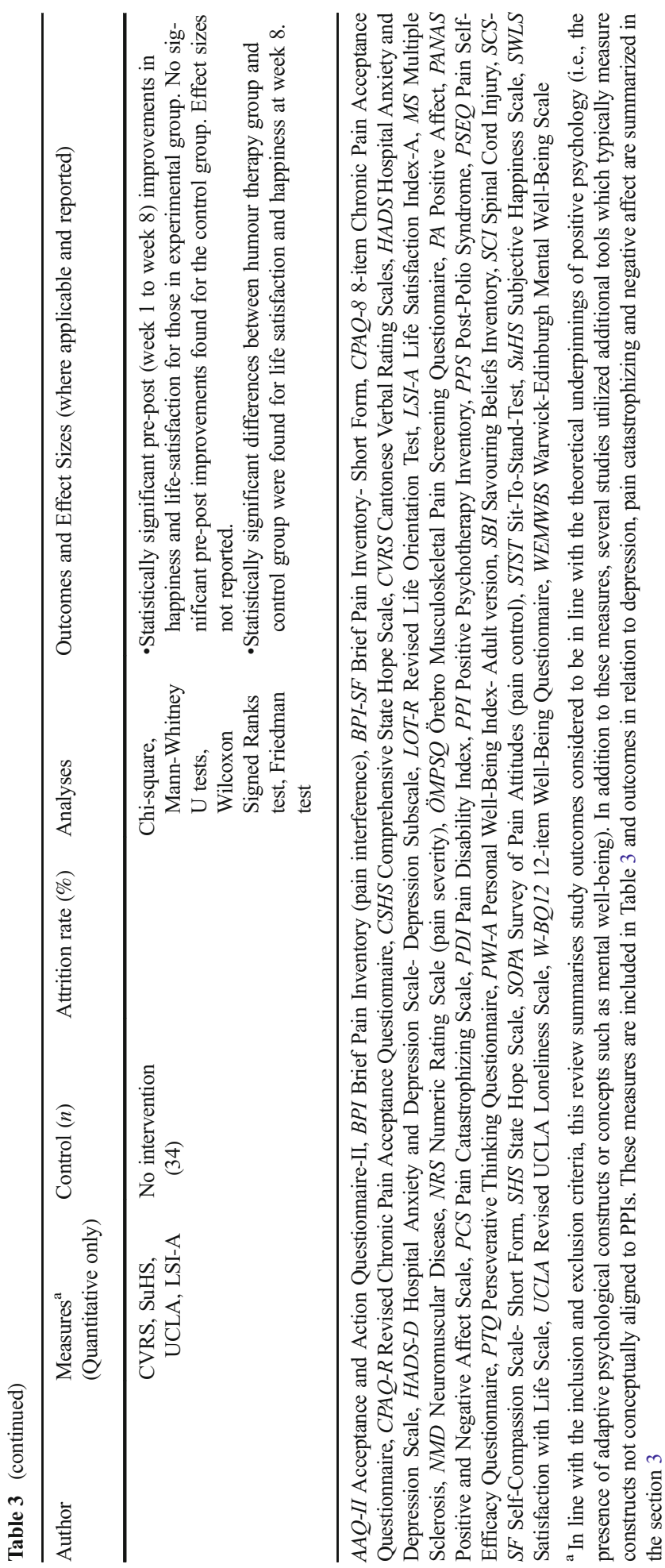




\subsection{Quantitative Cohort Studies}

\subsubsection{Well-Being}

Three studies, described in two publications (Howell et al. 2015; Simm et al. 2014), evaluated the impact of PPIs upon psychological well-being, with all reporting significant increases immediately following intervention. It is noteworthy that the articles by Simm et al. (2014) and Howell et al. (2015) comprised the lowest and highest scoring papers on the QATSSD respectively.

When the three individual subscales of the well-being measure reported in Howell et al.'s (2015) two studies were investigated, significant increases in relation to the pleasure experienced by the participants, and sense of engagement in life were observed. Significant increases in participants' levels of meaning (i.e., purpose in life) were also noted in the second of the studies reported in the paper (Study B; Howell et al. 2015), though no such increases were found in the first (Study A; Howell et al. 2015). Of these studies which measured well-being as an outcome variable, only Simm et al. (2014) investigated the longer-term effects of the PPI employed, with significant improvements maintained at ten-week, six-month and 12-month follow-ups.

\subsubsection{Hope}

Two studies explored the effects of a PPI in relation to hope (Howell et al. 2015). The outcomes of Study A demonstrated a trend for state hope scores to increase following the PPI, though these differences were non-significant. Similar results were observed in the second of the two studies, with pre-post improvements in overall state hope scores found to be non-significant. Interestingly, closer examination of results in Study B indicated that increases in state hope reflected significant change on the Pathway (the ability to generate several routes to pursue goals) subscale, but not the Agency (the perceived capacity to use one's pathways to reach goals) subscale, which when combined rendered the overall pre-post change in state-hope non-significant. Thus, participants reported an increased ability to identify the paths required to accomplish their personal goals (i.e., the 'way') following the PPI. However participants' perceived sense of agency or requisite motivations (i.e., the 'will') to undertake the necessary routes the remained unchanged.

Howell et al.'s (2015) Study B additionally incorporated a more comprehensive measure of hope, and improvements in participants' levels of hope following the PPI were found to be significantly greater following completion of the programme. A breakdown of these results suggested that this overall improvement in hope reflected statistically significant pre-post differences on the Mastery, Attachment and Survival (but not Spirituality) subscales. Whilst outcomes provide tentative evidence supporting the use of the hope-based psychological interventions, findings are limited due to the small samples sizes utilized in both studies.

\subsubsection{Life Satisfaction}

Two cohort studies assessed the effects of PPIs on life-satisfaction (Tse et al. 2010; Müller et al. 2015). Both studies found life-satisfaction significantly 
improved immediately following intervention, with Müller et al. (2015) reporting pre to post-treatment effect sizes as comparable to those in evaluations of CBT interventions for individuals with physical disabilities. The participants in the control group employed in Tse et al.'s (2010) study received no active intervention, and as expected no improvements in life-satisfaction for this cohort were thus found. The control group utilized in Müller et al. (2015) study were instructed to take part in a neutral weekly-writing activity to control for the effects of time and participation in an intervention. Although this intervention was not a PPI, significant post-treatment increases in life-satisfaction were also found amongst control group participants, with a small to medium effect size $(d=.36)$. However, whilst significant improvements in life-satisfaction were maintained 2.5 months following completion of the PPI for the treatment group, no significant maintenance of effect was observed for the control group in this study.

\subsubsection{Positive Affect}

Müller et al. (2015) additionally investigated the effects of the PPI on positive affect (PA), and found a statistically significant increase immediately post-intervention for the treatment group (but not control), though this improvement was not maintained at the 2.5 month follow-up.

\subsubsection{Happiness}

Tse et al. (2010) also evaluated the effects of the PPI in relation to participants' levels of happiness. Significant pre and post-treatment improvements were found amongst those who took part in the intervention. Control participants' self-report happiness levels remained stable throughout the duration of the study. Furthermore, during the final week, the difference between the levels of happiness reported by the two groups was statistically significant, with those who participated in the PPI reporting greater levels of happiness than those who received no therapeutic input.

\subsubsection{Pain Self-Efficacy}

Simm et al. (2014) additionally investigated the effects of the PPI upon pain selfefficacy, and found significant improvements immediately post-intervention and at the ten-week follow-up. No such maintenance of improvements were observed in the six and 12-months following completion of the programme.

\subsection{Additional Psychosocial Outcomes}

We excluded studies from the review which only reported results in relation to changes or reductions in unwanted maladaptive psychological processes or constructs. However, a number of the studies reported these more negatively-focused psychosocial outcomes alongside those captured using measures deemed to be more conceptually aligned with PPIs. 


\subsubsection{Depression}

Müller et al. (2015) found a significant reduction in participants' depressive symptoms immediately following completion of the PPI, with a small to medium effect size reported $(d=.40)$. These improvements were maintained at a 2.5 month follow-up. No significant improvements in depressive symptoms were evident within the control group.

\subsubsection{Negative Affect}

Müller et al. (2015) also examined differences in pre and post scores in relation to negative affect for both the active intervention and control groups. No significant changes in negative affect were evident for either group.

\subsubsection{Pain Catastrophizing}

Howell et al. (2015) measured pain catastrophizing in both of their studies. No significant differences between pre and post intervention scores were found in Study A, though the change within the mean scores was in expected direction and the effect size was small to medium in magnitude $(d=.37)$. Significant reductions in pain catastrophizing were observed in Study B and the effect size was medium in magnitude $(d=.60)$. Again, findings are limited given the small sample sizes employed in both studies. Müller et al. (2015) found a significant reduction in pain catastrophizing following the PPI, and a small effect size was reported $(d=.27)$. This improvement was not maintained at a 2.5 month follow up. No significant improvement in pain catastrophizing was evident for the control group post intervention.

\subsection{Single-Case Design Study}

One study (Flink et al. 2015) utilized a replicated single-case methodology whereby a sample of five participants completed self-report measures assessing a wide range of outcomes over a many time points, including before, during and after the PPI. The results indicated improvement across many of the variables for four of the five individuals in the study, though only a limited number of these pre-post differences were found to be reliable according to the Reliable Change Index (RCI). Lifesatisfaction was found to have reliably increased for two participants post-intervention, and a reliable improvement in PA was observed for one individual, which was maintained at a three-month follow-up. Optimism remained fairly stable for all participants across the study. Flink et al. (2015) additionally reported outcomes in relation to more negatively-focused psychosocial variables. The most consistent improvements were in relation to pain catastrophizing, with three individuals reported lower levels immediately following intervention (though only two pre-post differences were found to be reliable according to the RCI). Furthermore, only two participants reported outcomes suggesting reliable change in relation to improved depression and anxiety. Whilst there are methodological advantages of utilising the RCI as an objective measure of change, the study's authors note that the stringent criteria led to many non-significant findings, despite somewhat large improvements in scores noted. 


\subsubsection{Sensory/Physical Outcomes}

Five of the six quantitative studies assessed participants' sensory and physical experiences of the pain, and findings across the studies are somewhat inconsistent (see Table 1 for the measures used in each study). Two studies (Howell et al. 2015, Study A; Simm et al. 2014) found no significant reductions in participants' ratings of pain intensity and pain-related interference upon everyday functioning following the PPIs. Conversely, statistically significant reductions in pain intensity $(d=.65)$ and interference $(d=.56)$ were reported by participants who underwent the tailored PPI in Müller et al. (2015) study. These improvements were maintained at the ten-week follow-up. No such decreases in pain intensity and interference were found for the control group in the study, however relative to baseline levels, significant improvements in pain intensity, but not interference, were reported amongst controls at follow-up. Tse et al. (2010) similarly found significant improvements in pain scores immediately following the PPI, though no reductions in pain were reported in the control group.

The single-case design study by Flink et al. (2015) similarly revealed a mixed array of results. Pain intensity was assessed daily in the study and the authors note that the large variability in ratings both between and within individuals made it difficult to interpret the outcomes. Consistent improvements in participants' weekly ratings of pain-related disability were observed for four of the five individuals in the study, though only two of these reductions in pain-related disability were found to be indicative of reliable change according to the RCI.

\subsection{Qualitative Studies}

Two studies (Dargan et al. 2014; Larsen et al. 2015) reported qualitative themes which reflected improvements relevant to positive psychological constructs (e.g., flourishing). Dargan et al. (2014) described themes relating to participants' experiences of attending a PPI. One theme (i.e., 'Accessing the programme') reflected the initial effects that being invited to take part in the PPI had upon the individual, in terms of inducing a feeling of hope within participants that the intervention may lead to increased sense of control and greater independence. Other themes ('A solution-focused group' and 'The solution-focused clinician') reflected upon the PPI process and the beneficial effects experienced as a result. The theme 'Solutions and changes' encapsulated an increased sense within some participants of their ability to facilitate meaningful and positive change, indicating enhancements in pain-related self-efficacy.

Larsen et al. (2015) explored the impact of a group-based PPI in terms of its influence upon participants' sense of hope. The theme 'Awareness' suggested that the PPI enabled participants to better-recognise and reflect upon their own personal strengths and internal resources, despite the enduring nature of the chronic pain. The theme 'Community' related to the supportive atmosphere experienced by group members, which in turn led to participants feeling hopeful about the intervention and support they may receive. The positive impact of the clinicians delivering the PPI (through modelling positive conversations and demonstrating a genuine curiosity of participant's strengths) was found to be important in both qualitative studies, the effects of which led to an enhanced sense of hope and validation in participants. Both studies recognised 
these factors to be particularly relevant in the context of chronic pain, where individuals may experience a continual fear of judgement given the 'invisible' nature of their condition.

\section{Discussion}

The aim of this review was to collate, summarize and appraise studies which reported psychosocial outcomes of PPIs for individuals with chronic pain. Across all six of the quantitative studies, positive effects demonstrating immediate improvements in study variables relating to well-being, hope, pain selfefficacy, happiness and life-satisfaction were evident, suggesting that the effects of attending a PPI may be of benefit to those living with chronic pain. There was slight variation with respect to effect sizes across studies, with the majority categorised as medium to large. Many of the themes generated in the two qualitative studies similarly encapsulated the enhancement of positive psychological constructs such as hope and pain self-efficacy. Three studies (Simm et al. 2014; Müller et al. 2015; Flink et al. 2015) investigated the longer-term effects of the PPIs though the findings suggest a mixed pattern of maintenance.

Just two quantitative studies included a control group, and only one (Müller et al. 2015) of these reported effect sizes to give an indication of the magnitude of the differences between the group means at time one and time two. It is therefore important that effect sizes reported in the other quantitative studies are interpreted in light of the absence of control groups. For example, the findings of this review suggest that effect sizes were predominantly moderate to large, however a small to medium effect size was found for the control group in Müller et al. (2015) study. Although this one study suggests that the benefits gained from undergoing the PPI were greater than those acquired from receiving the control intervention, the lack of statistical data derived from inactive control groups across the remaining studies makes it difficult to infer the magnitude of the effects of the PPIs.

The review findings support existing theories regarding the factors associated with adaptive psychological functioning despite the enduring nature of pain. In line with existing mediation research whereby the presence of positive psychological constructs facilitate greater coping and adjustment (Skidmore et al. 2015; Wright et al. 2011), pre and post-intervention changes in self-efficacy (Simm et al. 2014) and hope (Howell et al. 2015) were associated with significant improvements in psychological well-being. Although increased levels of optimism have also been found to be related to greater adjustment in individuals with chronic pain (Wright et al. 2011), only one study (Flink et al. 2015) included this variable, with no significant changes in optimism observed following intervention.

The mechanisms underpinning specific PPIs delivered to those with chronic pain varied from study to study, though overall aims of interventions were to support individuals to identify meaningful goals, internal strengths and to notice and savour positive moments, despite the presence of pain. These initial findings demonstrating the positive effects of PPIs may contribute to increased patient choice of psychological treatments for those accessing pain services in the future. 


\subsection{Strengths and Limitations}

The poor methodological quality of some studies included in this review necessitate that appropriate caution is given with respect to the conclusions drawn. The heterogeneity of the PPIs themselves, the positive psychological constructs measured and study designs employed makes it somewhat difficult to draw firm conclusions regarding the consistency of these effects. It is notable that although there were marked differences with respect to participants' improvements described in each of the studies, all studies reported some degree of positive effect following treatment. It is currently unclear whether this observation reflects a publication bias within the existing literature, or perhaps the nascent nature of the evidence base at present.

To the best of our knowledge, this review is the first attempt to systematically examine the effects of PPIs amongst individuals living with chronic pain. Whilst examination of this specific clinical area contributes novel insight and complements the chronic pain and positive psychology literature, there are limitations of the review procedure itself. First, the inclusion criteria were somewhat broad and resulted in studies detailing interventions which were congruous with the underlying principles of positive psychology, though varied somewhat in terms of their content and exercises. However, given the ongoing debate within this field and the aim of this review was to collate the available evidence to identify the impact of PPIs on psychosocial factors within pain populations (as opposed to establishing the clinical effectiveness of such interventions), we chose not to adopt criteria which were too conservative or narrow to reduce the risk of excluding relevant research. We also acknowledge there may be related terms such as 'training' (+, 'exercise' and 'prevention') which future reviews may include.

For the purpose of this review, we chose to solely include papers which utilized at least one outcome measure deemed to be conceptually aligned to positive psychology (i.e., those which allow for the assessment of flourishing). Thus, studies of PPIs which used more traditional measures of psychological distress or affective symptomatology (to potentially measure reductions in languishing) only were not included. We acknowledge the possible bias which may arise from omitting studies which solely administered measures of this nature, and we have attempted to address this by including findings in relation to these variables as part of the synthesis of results.

\subsection{Clinical and Research Implications}

A common therapeutic technique utilized in all but one of the studies involved inviting participants to imagine their 'best possible' or 'hoped for' future selves. The specific exercises used to initiate this positive and future-focused type of thinking varied across studies (e.g., writing detailed descriptions, doing visualization exercises or sharing verbal descriptions), though the overarching aim was to increase participants' sense of optimism for the future, despite the presence of pain.

Tentatively, individuals with chronic pain may benefit from practicing 'best possible' or 'hoped for' future selves exercises, though this assumption requires further investigation. To date, no studies have directly compared outcomes across PPIs which include and omit specific exercises, and only one study in this review (Flink et al. 2015) examined the effects of these exercises on participants' levels of optimism. It is 
therefore premature to draw inferences about the effectiveness of particular exercises utilized in PPIs. Future research is needed to examine the unique contribution of specific exercises in relation to improved optimism and psychological well-being, taking into account their individual effectiveness and added value in PPIs.

It is noteworthy that the majority of PPIs (six of the eight studies) were delivered in a group format. In line with a biopsychosocial model (Gatchel et al. 2007), whereby pain is understood in terms of its multi-faceted impact upon an individual's experience, it is anticipated that the social components and interactions within the group setting contributed to individuals' increased sense of psychological well-being. Future research should compare the effectiveness of PPIs delivered across a range of differing methods (e.g., groups, individual sessions and online interventions) to further examine and better understand the potential benefit of PPIs delivered in group formats.

Although the final review only included studies with adult samples, we did not uncover any relevant articles which utilized child or adolescent populations during the literature search. Given that some authors claim that the incidence of chronic pain amongst children and adolescents is comparable to that of adults (Eccleston \& Malleson 2003), future research should address and evaluate the current state of the positive psychological literature with this clinical population in addition to investigating adult samples. Furthermore, future exploration may investigate the effects of PPIs on specific pain conditions or types (e.g., nociceptive or neuropathic pain). A striking finding in this review (particularly given the somewhat recent publication dates of many of the studies) was the apparent lack of evidence for the involvement of individuals with pain in study design processes. Given the increasing awareness of the value of patient involvement in healthcare research (Carter et al. 2013), future researchers should look to embrace and utilise the expertise of those with livedexperience of chronic pain.

\subsection{Conclusion}

The findings of this review extend the existing evidence and outline the effects of PPIs upon well-being applied within chronic pain populations, in addition to a wider array of outcome variables relevant to the core aims and underpinnings of positive psychological approaches. It provides a useful summary of the state of the available literature at present and notably identifies the relative lack of high quality studies within this specific clinical area, pointing to the importance of future research to advance this field.

The findings demonstrate initial support for the use of PPIs to enhance constructs relevant to positive psychology and psychological well-being amongst individuals living with chronic non-cancer pain. There is a need for a greater consensus amongst researchers regarding core elements and definition of PPIs and measurement of outcomes, and from this high-quality trials should be undertaken in order that one may begin to investigate the effectiveness of such interventions alongside more-widely used treatments. Researchers should work towards a more encompassing definition of the core elements of a PPI and identify key, conceptually-aligned outcomes to measure subsequently. This convergence of thoughts and ideas will allow for the generation of higher-quality evidence regarding the effects of PPIs, potentially leading to greater patient-choice in clinical services. 
Acknowledgements Acknowledgement and thanks to Laura $\mathrm{O}^{\prime}$ Brien-King for her contribution to the article identification and data extraction processes.

\section{References}

Boersma, K., \& Linton, S. (2006). Expectancy, fear and pain in the prediction of chronic pain and disability: a prospective analysis. European Journal of Pain, 10, 551-557. doi:10.1016/j.ejpain.2005.08.004.

Bolier, L., Haverman, M., Westerhof, G. J., Riper, H., Smit, F., \& Bohlmeijer, E. (2013). Positive psychology interventions: a meta-analysis of randomized controlled studies. BMC Public Health, 13, 119. doi:10.1186 /1471-2458-13-119.

Bolier, L., Haverman, M., Westerhof, G. J., Riper, H., Smit, F., \& Bohlmeijer, E. (2014). Looking at the bowl of fruit or focussing on the apples? Reply to the comments of Schueller et al. International Journal of Wellbeing, 4(1), 99-105. doi:10.5502/ijw.v4i1.6.

Braun, V., \& Clarke, V. (2006). Using thematic analysis in psychology. Qualitative Research in Psychology, 3(2), 77-101. doi:10.1191/1478088706qp063oa.

Breivik, H., Collett, B., Ventafridda, V., Cohen, R., \& Gallacher, D. (2006). Survey of chronic pain in Europe: prevalence, impact on daily life, and treatment. European Journal of Pain, 10, 287-333. doi:10.1016/j. ejpain.2005.06.009.

Carter, P., Beech, R., Coxon, D., Thomas, M. J., \& Jinks, C. (2013). Mobilising the experiential knowledge of clinicians, patients and carers for applied health-care research. Contemporary Social Science. doi:10.1080 /21582041.2013.767468.

Dahl, J., Wilson, K. G., \& Nilsson, A. (2004). Acceptance and commitment therapy and the treatment of persons at risk for long-term disability resulting from stress and pain symptoms: a preliminary randomized trial. Behavior Therapy, 35, 785-801. doi:10.1016/S0005-7894(04)80020-0.

Dargan, P. J., Simm, R., \& Murray, C. (2014). New approaches towards chronic pain: patient experiences of a solution-focused pain management programme. British Journal of Pain, 8(1), 34-42. doi:10.1177 /2049463713516755.

Eccleston, C., \& Malleson, P. (2003). Managing chronic pain in children and adolescents: we need to address the embarrassing lack of data for this common problem. British Medical Journal, 326(7404), 1408-1409. doi:10.1136/bmj.326.7404.1408.

Emmons, R. A., \& McCullough, M. E. (2003). Counting blessings versus burdens: an experimental investigation of gratitude and subjective well-being in daily life. Journal of Personality and Social Psychology, 84, 377-389.

Flink, I. K., Smeets, E., Bergbom, S., \& Peters, M. L. (2015). Clinical pain research: happy despite pain: pilot study of a positive psychology intervention for patients with chronic pain. Scandinavian Journal of Pain, 7, 71-79. doi:10.1016/j.sjpain.2015.01.005.

Flor, H., \& Turk, D. C. (2011). Chronic pain: an integrated biobehavioral perspective. Seattle: IASP Press.

Fordyce, G. (2001). Pain in cancer and chronic non-cancer conditions: similarities and differences. Acta Anaesthesiologica Scandinavica, 45(9), 1086-1089. doi:10.1034/j.1399-6576.2001.450906.x.

Gander, F., Proyer, R. T., \& Ruch, W. (2016). Positive psychology interventions addressing pleasure, engagement, meaning, positive relationships, and accomplishment increase well-being and ameliorate depressive symptoms: a randomized, placebo-controlled online study. Frontiers in Psychology, 7, 686. doi:10.3389/fpsyg.2016.00686.

Gatchel, R. J., Peng, Y. B., Peters, M. L., Fuchs, P. N., \& Turk, D. C. (2007). The biopsychosocial approach to chronic pain: scientific advances and future directions. Psychological Bulletin, 133(4), 581-624. doi:10.1037/0033-2909.133.4.581.

Hone, L. C., Jarden, A., Schofield, G. M., \& Duncan, S. (2014). Measuring flourishing: the impact of operational definitions on the prevalence of high levels of wellbeing. International Journal of Wellbeing, 4(1), 62-90. doi:10.5502/ijw.v4i1.4.

Howell, A. J., Jacobson, R. M., \& Larsen, D. J. (2015). Enhanced psychological health among chronic pain clients engaged in hope-focused group counseling. The Counseling Psychologist, 43(4), 586-613. doi:10.1177/0011000014551421.

International Association for the Study of Pain (IASP) (1994). Classification of chronic pain (Second ed.). Seattle: IASP Press. 
Jackson, J. L., George, S., \& Hinchey, S. (2009). Medically unexplained physical symptoms. Journal of General Internal Medicine, 24(4), 540-542. doi:10.1007/s11606-009-0932-x.

Jensen, M. P., \& Turk, D. C. (2014). Contributions of psychology to the understanding and treatment of people with chronic pain. The American Psychologist, 62(2), 105-118. doi:10.1037/a0035641.

Kabat-Zinn, J. (2013). Full catastrophe living: using the wisdom of your body and mind to face stress, pain, and illness. New York: Bantam Books. doi:10.1002/shi.88.

Keyes, C. L. M. (2005). Mental illness and/or mental health? Investigating axioms of the complete state model of health. Journal of Consulting and Clinical Psychology, 73, 539-548. doi:10.1037/0022-006 X.73.3.539.

Keyes, C. L. M. (2011). Toward a science of mental health. In S. J. Lopez \& C. R. Snyder (Eds.), Oxford handbook of positive psychology (pp. 89-95). New York: Oxford University Press.

Koch, L., Jansen, L., Brenner, H., \& Arndt, V. (2013). Fear of recurrence and disease progression in long-term ( $\geq 5$ years) cancer survivors: a systematic review of quantitative studies. Psychooncology, 22(1), 1-11. doi:10.1002/pon.3022.

Larsen, R. J., \& Prizmic, Z. (2004). Affect regulation. In K. D. Vohs \& R. F. Baumeister (Eds.), Handbook of self-regulation: research, theory, and applications (pp. 40-61). New York: Guilford Press.

Larsen, D. J., King, R. L., Stege, R., \& Egeli, N. A. (2015). Hope in a strengths-based group activity for individuals with chronic pain. Counselling Psychology Quarterly, 28(2), 175-199. doi:10.1080 /09515070.2015.1007444.

Lopez, S. J., \& Snyder, C. R. (2003). Positive psychological assessment: a handbook of models and measures. Washington: American Psychological Association.

Marikar Bawa, F. L., Mercer, S. W., Atherton, R. J., Clague, F., Keen, A., Scott, N. W., \& Bond, C. M. (2015). Does mindfulness improve outcomes in patients with chronic pain? Systematic review and meta-analysis. The British Journal of General Practice, 65(635), 387-400. doi:10.3399/bjgp15X685297.

McBeth, J., Macfarlane, G. J., \& Silman, A. J. (2002). Does chronic pain predict future psychological distress? Pain, 96(3), 239-245. doi:10.1016/S0304-3959(01)00452-3.

McGrath, P. A. (2005). Children- not simply "little adults”. In H. Merskey, J. D. Loeser, \& R. Dubner (Eds.), The paths of pain (pp. 433-446). Seattle: IASP Press.

Müller, R., Gertz, K. J., Molton, I. R., Terrill, A. L., Bombardier, C. H., Ehde, D. M., \& Jensen, M. P. (2015). Effects of a tailored positive psychology intervention on well-being and pain in individuals with chronic pain and a physical disability: a feasibility trial. The Clinical Journal of Pain, 32(1), 32-44. doi:10.1097 /AJP.0000000000000225.

Niv, D., \& Devor, M. (2004). Chronic pain as a disease in its own right. Pain Practice, 4, 179-181.

Otake, K., Shimai, S., Tanaka-Matsumi, J., Otsui, K., \& Fredrickson, B. L. (2006). Happy people become happier through kindness: a counting kindnesses intervention. Journal of Happiness Studies, 7, 361-375. doi:10.1007/s10902-005-3650-z.

Parks, A. C., \& Biswas-Diener, R. (2013). Positive interventions: past, present and future. In T. Kashdan \& J. Ciarrochi (Eds.), Bridging acceptance and commitment therapy and positive psychology: a practitioner's guide to a unifying framework (pp. 140-165). Oakland: New Harbinger.

Qi, X., Yang, M., Ren, W., Jia, J., Wang, J., Han, G., \& Fan, D. (2013). Find duplicates among the PubMed, EMBASE, and Cochrane library databases in systematic review. PloS One, 8(8). doi:10.1371/journal. pone. 0071838 .

Schueller, S. M., Kashdan, T. B., \& Parks, A. C. (2014). Synthesizing positive psychological interventions: suggestions for conducting and interpreting meta-analyses. International Journal of Wellbeing, 4(1), 9198. doi:10.5502/ijw.v4i1.5.

Schug, S. A., \& Auret, K. (2008). Clinical pharmacology: principles of analgesic drug management. In N. Sykes, M. I. Bennett, \& C. S. Yuan (Eds.), Clinical pain management: cancer pain (2nd ed., pp. 104 122). London: Hodder Arnold.

Segal, Z. J., Williams, M. G., \& Teasdale, J. D. (2002). Mindfulness-based cognitive therapy for depression: a new approach to preventing relapses. New York: Guildford Press.

Seligman, M. E. P. (2002). Authentic happiness: using the new positive psychology to realize your potential for lasting fulfillment. New York: Free Press.

Seligman, M. E. P. (2011). Flourish: a new understanding of happiness and well-being - and how to achieve them. London: Nicolas Brealey Publishing.

Seligman, M. E. P., \& Csikszentmihalyi, M. (2000). Positive psychology: an introduction. The American Psychologist, 55(1), 5-14. doi:10.1037/0003-066X.55.1.5.

Simm, R., Iddon, J., \& Barker, C. (2014). A community pain service solution-focused pain management programme: delivery and preliminary outcome data. British Journal of Pain, 8(1), 49-56. doi:10.1177 /2049463713507910. 
Sin, N. L., \& Lyubomirsky, S. (2009). Enhancing well-being and alleviating depressive symptoms with positive psychology interventions: a practice-friendly meta-analysis. Journal of Clinical Psychology, 65(5), 467-487. doi:10.1002/jclp.20593.

Sirriyeh, R., Lawton, R., Gardner, P., \& Armitage, G. (2012). Reviewing studies with diverse designs: the development and evaluation of a new tool. Journal of Evaluation in Clinical Practice, 18, 746-752. doi:10.1111/j.1365-2753.2011.01662.x.

Skidmore, J. R., Koenig, A. L., Dyson, S. J., Kupper, A. E., Garner, M. J., \& Keller, C. J. (2015). Pain selfefficacy mediates the relationship between depressive symptoms and pain severity. The Clinical Journal of Pain, 31(2), 137-144. doi:10.1097/AJP.0000000000000094.

Smith, B. H., Elliott, A. M., Chambers, W. A., Smith, W. C., Hannaford, P. C., \& Penny, K. (2001). The impact of chronic pain in the community. Family Practice, 18, 292-299. doi:10.1093/fampra/18.3.292.

Tse, M. M. Y., Lo, A. P. K., Cheng, T. L. Y., Chan, E. K. K., Chan, A. H. Y., \& Chung, H. S. W. (2010). Humor therapy: relieving chronic pain and enhancing happiness for older adults. Journal of Aging Research, 2010, 343574-343574. doi:10.4061/2010/343574.

Turk, D. C., Wilson, H. D., \& Cahana, A. (2011). Treatment of chronic non-cancer pain. Lancet, 377(9784), 2226-2235. doi:10.1016/S0140-6736(11)60402-9.

van der Windt, D., Kuijpers, T., Jellema, P., van der Heijden, G., \& Bouter, L. (2007). Do psychological factors predict outcome in both low-back pain and shoulder pain? Annals of the Rheumatic Diseases, 66, 313-319. doi:10.1136/ard.2006.053553.

Veehof, M. M., Oskam, M., Schreurs, K. M. G., \& Bohlmeijer, E. T. (2011). Acceptance based interventions for the treatment of chronic pain: a systematic review and meta-analysis. Pain, 152(3), 533-542. doi:10.1016/j.pain.2010.11.002.

Von Korff, M., Lin, E., Fenton, J., \& Saunders, K. (2007). Frequency and priority of pain patients' health care use. The Clinical Journal of Pain, 23, 400-408. doi:10.1097/AJP.0b013e31804ac020.

Williams, S., Eccleston, C., \& Morley, A. (2012). Psychological therapies for the management of chronic pain (excluding headache) in adults. Cochrane Database of Systematic Reviews, 14(11). doi:10.1002 /14651858.CD007407.pub3.

Wing, J. F., Schutte, N. S., \& Byrne, B. (2006). The effect of positive writing on emotional intelligence and life satisfaction. Journal of Clinical Psychology, 62, 1291-1302. doi:10.1002/jclp.20292.

Wright, M. A., Wren, A. A., Somers, T. J., Goetz, M. C., Fras, A. M., Huh, B. K., Rogers, L. L., \& Keefe, F. J. (2011). Pain acceptance, hope, and optimism: relationships to pain and adjustment in patients with chronic musculoskeletal pain. The Journal of Pain, 12(11), 1155-1162. doi:10.1016/j.jpain.2011.06.002. 